\title{
Cytokine responses to symbiotic and lactoferrin combination in very low birth weight neonates: a randomized control trial
}

\author{
Ozge Serce Pehlevan M.D., Associate professor ${ }^{a}$, Derya Benzer M.D. ${ }^{a}$, \\ Tugba Gursoy M.D., Professor ${ }^{b}$, Esin Aktas Cetin M.D., Associate professorc, \\ Guner Karatekin M.D., Professor ${ }^{a}$ and Fahri Ovali MD, Professor ${ }^{a}$
}

\begin{abstract}
Introduction. Probiotics and prebiotics, which are multifunctional agents, have potential benefits in chronic mucosal inflammation, including the prevention of necrotizing enterocolitis. However, the mechanisms and the results of these immunomodulatory effects are not clear. This study aimed to investigate the cytokine response to the combination of Lactobacillus and Bifidobacterium together with fructo- and galactooligosaccharides (symbiotic) and lactoferrin in very low birth weight neonates.

Population and Methods. Infants $\leq 32 \mathrm{GWs}$ and $\leq 1,500$ g were randomly assigned to receive a symbiotic combination or $1 \mathrm{ml}$ distilled water as placebo starting with the first feed until discharge. Blood samples were obtained at postnatal $0 \pm 2,14 \pm 2$, and $28 \pm 2$ days, and the serum levels of interferon- $\gamma$, interleukin (IL)-5, IL-10, and IL-17A were measured.
\end{abstract}

Results. In the study group $(\mathrm{n}=25)$, the IL-10 levels decreased throughout the study period $(p=0.011)$ but did not change in the control group. The IL-5levels remained steady in the first 14 days and decreased significantly thereafter $(p=0.042)$ in the study group, whereas they increased in the first 14 days $(\mathrm{p}=0.019)$, and then decreased in 28 days $(\mathrm{p}=0.011)$ in the control group $(\mathrm{n}=25)$. The levels of the other cytokines did not change throughout the study period.

Conclusion. The combined use of probiotics with oligosaccharides and lactoferrin was associated with a decrease in IL-10 levels, but no change was observed in the other cytokines.

Keywords: cytokines, lactoferrin, necrotizing enterocolitis, prebiotics, probiotics.

http:/ / dx.doi.org/10.5546/aap.2020.eng.e8

To cite: Serce Pehlevan O, Benzer D, Gursoy T, Aktas Cetin E, et al. Cytokine responses to symbiotic and lactoferrin combination in very low birth weight neonates: a randomized control trial. Arch Argent Pediatr 2020;118(1):e8-e15.

\section{INTRODUCTION}

Postnatally colonized bacteria communicate with the intestinal cells and activate the immune response, enterocyte development, and mucosal barrier function during gastrointestinal tract development. ${ }^{1}$ Probiotic microorganisms improve the microbiota of the gut when this colonization is inappropriate. , $^{23}$ Prebiotics such as oligosaccharides stimulate the growth and activity of these microorganisms and provide substrates for them. ${ }^{2,3}$ Many factors disrupt preterm neonates' microbiota. ${ }^{2}$ Dysbiosis in this population can cause necrotizing enterocolitis (NEC). ${ }^{1}$ Immaturity of the gut, dysregulated inflammatory response, and incomplete bacterial colonization are the major pathways in NEC pathogenesis. ${ }^{4}$

Breastfeeding, which reduce the incidence of NEC, is associated with the improved expression of beneficial bacteria such as Bifidobacteria and Lactobacillus with the help of its ingredients, such as oligosaccharides, lysozymes, and lactoferrin. ${ }^{1}$ Lactoferrin has potent immunomodulatory and broadspectrum antimicrobial activities. ${ }^{5}$ It influences enterocyte differentiation, growth, and proliferation, and decreases sepsis and NEC incidence in neonates. ${ }^{5}$ Conversely, the roles of other prebiotics in NEC prophylaxis are conflicting. ${ }^{6-8}$ The Cochrane collaboration, including randomized control trials (RCTs) with different types of probiotics, supports the use of probiotics to prevent NEC. ${ }^{9}$ Combining these different strains in symbiotic supplements is an 
alternative strategy, but the results of RCTs are contradictory as the probiotic function is strain specific. ${ }^{10-12}$ Some probiotic strains increase proinflammatory cytokines, whereas others induce anti-inflammatory cytokine responses. ${ }^{13}$ However, what happens if the balance between pro- and anti-inflammatory responses shifts to one side is an unanswered question. Can probiotic combinations that are expected to decrease NEC incidence be hazardous to the host because of their strain-specific effects?

The proinflammatory Th1-type cytokines like interferon (IFN)- $\gamma$ promote cell-mediated immunity, whereas the Th2-type cytokines like interleukin-5 (IL-5) induce eosinophilic response and humoral immunity. ${ }^{12} \mathrm{~T}$ regulatory (Treg) cells like IL-10 suppress the aberrant immune response to self-antigens. ${ }^{12}$ Th17 cells have a role in the mucosal barriers. ${ }^{14}$ Inflammation is responsible for the development of morbidities in neonates. For example, reduced IL-10 level in cord blood was associated with the risk of bronchopulmonary dysplasia. ${ }^{15}$ The disturbance of IL-17/Th17 has an important role in the pathogenesis of retinopathy of prematurity. ${ }^{14}$ Therefore, probiotic strains that induce antiinflammatory cytokines may be beneficial in the management of inflammatory diseases, and the evaluation of inflammatory response produced in the host by these strains is important. ${ }^{12}$ Thus, we aimed to investigate the combined effect of Lactobacillus and Bifidobacterium together with oligosaccharides and lactoferrin on the different types of cytokines.

\section{POPULATION AND METHODS}

A prospective masked, placebo-controlled, and randomized trial was conducted in our neonatology unit from July to September 2013 after the approval of the ethics committee (July 20, 2012). Gestational age $\leq 32$ weeks VLBW neonates were eligible for the trial. The neonates with congenital anomalies and who were born to mothers with premature rupture of membranes (PROM) and/or chorioamnionitis were not included in the study. The neonates who had 1) mechanical ventilation more than 7 days, 2) culture-proven sepsis at the time of blood sampling, 3) NEC, 4) surgery, and 5 ) who died within the first 30 days of life were excluded from the study after randomization because of the potential effect of these factors on the cytokine levels.

The serum levels of the different types of cytokines, such as IL-5 (Th2 cell), IL-10 (Treg cell), IL-17A (Th17 cell), and IFN- $\gamma$ (Th1 cell) were determined in the immediate postnatal period and at the end of the second and fourth weeks. The neonates were randomly assigned to the study group or the control group in the first few hours of life using sequential numbers generated at the computer center after informed parental consent was obtained. The allocations were placed in sequentially numbered sealed envelopes. The study group received ISO9001-certified preparation that contained 820 million Lactobacillus (L.) rhamnosus [Korean collection for type culture (KCTC) no 12202BP], 410 million L. plantarum [KCTC 10782BP, L. casei (KCTC 12398BP)], Bifidobacterium (B.) lactis (KCTC 11904BP), 383 mg fructooligosaccharide, $100 \mathrm{mg}$ galactooligosaccharide, and $2 \mathrm{mg}$ bovine lactoferrin (NBL Probiotic-ATP, $1 / 2$ sachet every $12 \mathrm{~h}$ ). The control group received a placebo (distilled water; $1 \mathrm{~mL}$ per dose twice daily). The dosage of supplementation was determined by considering previous studies. ${ }^{16}$ The preparations, which were kept at room temperature and away from light and humidity, were added to breast milk or formula [Aptamil Prematil Formula (Milupa AG, Friedrichsdorf, Germany)] starting with the first feed until discharge. Following the instructions from the sealed envelope, the personnel in the breast milk team mixed the supplements with distilled water to prepare a $1 \mathrm{~mL}$ suspension and added it to the breast milk or formula before feeding; the addition of the suspension did not change the appearance of the milk. Thus, the only personnel who knew of the infants' group assignments were one of the investigators (TG) and those in the breast milk team who were not involved in the care of the infants and data analyses. Minimal enteral feeding $(10-20 \mathrm{~mL} / \mathrm{kg})$ was initiated on the first postnatal day if there was no contraindication (e.g., severe metabolic acidosis, asphyxia). A daily increase in the amount of feeding was based on birth weight $(10 \mathrm{~mL} / \mathrm{kg} /$ day for $<750 \mathrm{~g}, 20 \mathrm{~mL} / \mathrm{kg} /$ day for $750-1250 \mathrm{~g}$, and $30 \mathrm{~mL} / \mathrm{kg} /$ day for 1,250$1,500 \mathrm{~g}$ birth weight). Feedings were withheld if there was gastric aspirate in an amount that was more than one-half of the previous feeding with abdominal distension or vomiting. Fortification was started when the enteral feeding was more than $100 \mathrm{ml} / \mathrm{kg} / \mathrm{d}$. A fixed dosage $(4 \mathrm{~g}$ per $100 \mathrm{ml}$ human milk) of fortifier [Eoprotein (Milupa AG, Friedrichsdorf, Germany)] was added to the milk until the infant's birthweight was $\geq 2,500 \mathrm{~g}$. The infants received total parenteral nutrition until 
$100 \mathrm{~mL} / \mathrm{kg}$ / day of enteral feeding was achieved.

Infants with a birth weight below two standard deviations (SD) according to intrauterine growth curves were classified as small for gestational age. ${ }^{17}$ The modified Bell, Papile, and National Institute of Child Health and Human Development classifications were used to define $\mathrm{NEC}^{18}$, intraventricular hemorrhage ${ }^{19}$, and bronchopulmonary disease ${ }^{20}$, respectively.

The serum cytokine levels were determined using the solid-phase sandwich enzyme-linked immunosorbent assay (Diaclone, France) at postnatal $0 \pm 2,14 \pm 2$, and $28 \pm 2$ days). Blood samples were obtained between 8:00-10:00 am and immediately centrifuged for $10 \mathrm{~min}$ at 3,000 rpm. The serum samples were stored at $-80{ }^{\circ} \mathrm{C}$ until analysis. All assays were conducted according to the manufacturer's protocols. The samples were run in duplicate. The supplied standards were used to generate the standard curves. The samples and standards were applied to the wells that had been pre-coated with monoclonal antibodies specific for IL-5, IL-10, IL-17A, and IFN- $\gamma$. Unbound proteins were removed by washing, and biotin-conjugated and horseradish peroxidase-conjugated streptavidin

FIGURE 1. Flow diagram of the study

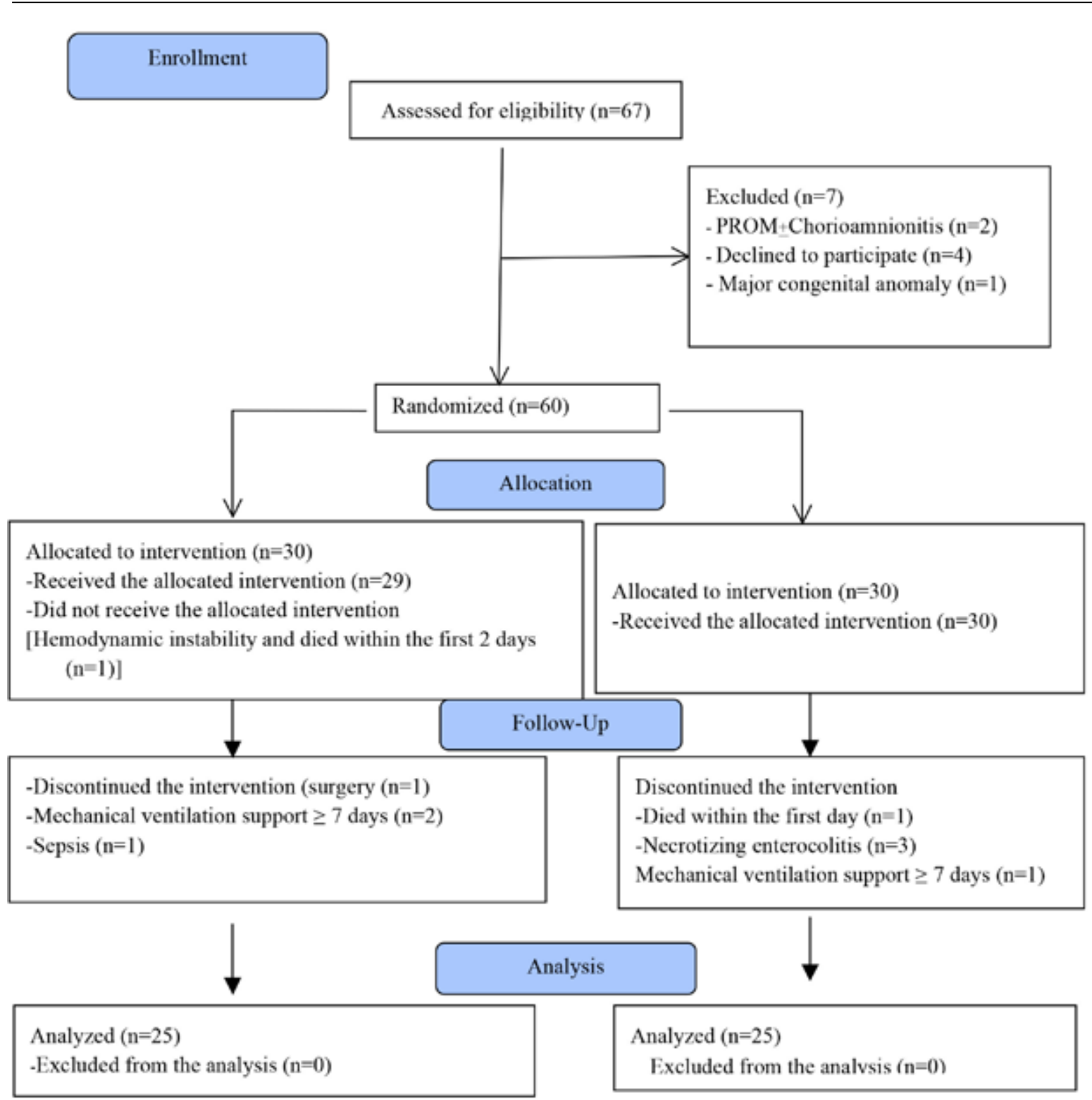


were added in a step-wise manner. After the color reaction with the substrate, the ELISA plates were assessed immediately at $450 \mathrm{~nm}$ and a wavelength correction of $620 \mathrm{~nm}$.

Statistical analyses were performed by the NCSS program (version 2007; Kaysville, Utah, USA). The descriptive analyses were presented using the ratio, mean $\pm S D$, and median (25-75p). The Mann-Whitney U test was used to compare the cytokine levels between the groups. Friedman tests were conducted to test the significance of change in the cytokine levels throughout the study period. The Wilcoxon test was performed to test the significance of the pairwise differences between day $0 \pm 2$ and $14 \pm 2$, between day $0 \pm 2$ and $28 \pm 2$, and between day $14 \pm 2$ and $28 \pm 2$ in each group. An overall $5 \%$ type-1 error level was used to infer the statistical significance for other statistics.

The study maintained $80 \%$ power, with at least 24 patients in each group showing a statistically significant difference of $0.75 \mathrm{SD}$ in the cytokine levels between the groups (i.e., $1.5 \mathrm{pg} / \mathrm{ml}$ difference when the $\mathrm{SD}$ is $2 \mathrm{pg} / \mathrm{mL}, 0.75 \mathrm{pg} / \mathrm{mL}$ when the $\mathrm{SD}$ is $1 \mathrm{pg} / \mathrm{mL}$, etc.) and $5 \%$ type- 1 error at each time point.

Ethics approval: The trial was approved by the central ethical committee in Ankara, Turkey.

Registration: This trial has been registered at www.clinicaltrials.gov with identifier number: NCT01899677

\section{RESULTS}

The flow diagram of the study is shown in Figure 1. Finally, 25 neonates in each group completed the study. The only difference in the characteristics of the groups was observed in the incidence of preeclampsia (Table 1). No adverse effects were observed.

The serum cytokine levels during the study period are shown in Figure 2 and Table 2. The IL10 levels decreased significantly throughout the study period in the study group $(\mathrm{p}=0.011)$. The IL-5 levels also decreased throughout the study period, but this decrease was not significant $(p=0.066)$. However, the decrease in IL-5 levels from day 14 to day 28 in the study group was significant $(p=0.042)$. In the control group, the serum levels of IL-5 increased significantly within the first 14 days $(p=0.019)$ but decreased on day $28(\mathrm{p}=0.011)$. The serum levels of IL-17A and IFN- $\gamma$ did not differ in both groups.

\section{DISCUSSION}

Inflammation has role in various morbidities of prematurity. ${ }^{14,15}$ Determining the strainspecific immunomodulatory effects of probiotics is important. Therefore, we focused on proinflammatory / anti-inflammatory cytokine balance, and anticipated anti-inflammatory response. We preferred a supplement that includes the elements of breast milk. The most important finding observed in this study was the

TABLE 1. Demographic and clinical characteristics of the groups

\begin{tabular}{|c|c|c|c|}
\hline & Study group $(n=25)$ & Control group $(n=25)$ & $p$ \\
\hline Birth weight (g), mean (SD) & $1266(228)$ & $1230(262)$ & 0.15 \\
\hline Gestational age (weeks), mean (SD) & $30.1(2.03)$ & $29.8(2.3)$ & 0.32 \\
\hline $5^{\text {th }}$ min. Apgar, median (25-75 p) & $8(6-8)$ & $7(6-8)$ & 0.91 \\
\hline Male infants, n (\%) & $12(48)$ & $18(64)$ & 0.27 \\
\hline Cesarean section, n (\%) & $24(96)$ & $25(89)$ & 0.61 \\
\hline Preeclampsia, n (\%) & $5(20)$ & $13(46)$ & 0.043 \\
\hline Antenatal steroid treatment, $\mathrm{n}(\%)$ & $22(88)$ & $22(78)$ & 0.47 \\
\hline Small for gestational age, $\mathrm{n}(\%)$ & $2(8)$ & $8(28)$ & 0.08 \\
\hline Respiratory distress syndrome, $\mathrm{n}(\%)$ & $6(24)$ & $11(39)$ & 0.23 \\
\hline Intraventricular hemorrhage, n (\%) & $8(32)$ & $9(32)$ & 0.99 \\
\hline Patent ductus arteriosus, n (\%) & $6(24)$ & $11(39)$ & 0.23 \\
\hline Chronic lung disease, $\mathrm{n}(\%)$ & $5(20)$ & $8(28)$ & 0.46 \\
\hline Postnatal day on which MEFa was started, median (25-75 p) & $2(1-2)$ & $2(1-2)$ & 0.36 \\
\hline$\%$ of breast milk used, median $(25-75 \mathrm{p})$ & $80(50-92)$ & $80(50-90)$ & 0.91 \\
\hline Weight on the $14^{\text {th }}$ day $(\mathrm{g})$, mean $(\mathrm{SD})$ & $1322 \pm 306$ & $1310 \pm 267$ & 0.89 \\
\hline Weight on the $28^{\text {th }}$ day $(\mathrm{g})$, mean (SD) & $1421 \pm 363$ & $1517 \pm 447$ & 0.54 \\
\hline Weight at discharge (g), mean (SD) & $1901 \pm 453$ & $1862 \pm 318$ & 0.72 \\
\hline Non-peroral day, mean (SD) & $1.8 \pm 3.1$ & $1.48 \pm 2.7$ & 0.67 \\
\hline
\end{tabular}

${ }^{\mathrm{a}} \mathrm{MEF}$, minimal enteral feeding. 
decrease in IL-10 levels in the symbiotic group throughout the study period. Preterm infants have a low ability to produce IL-10, which is necessary for intestinal homeostasis, and protects infants from NEC. ${ }^{21-24}$ Infants whose mothers have low levels of IL-10 are at increased risk for NEC. ${ }^{21,25}$

TABLE 2. Effect of the symbiotic preparation on the circulating values of IL-5, IL-10, IFN- $\gamma$, and IL-17A

\begin{tabular}{|c|c|c|c|}
\hline & Study group $(n=25)$ & Control group $(n=25)$ & $p^{\mathrm{a}}$ \\
\hline \multicolumn{4}{|c|}{ Interleukin-5 (pg/ml), median (25-75 p) } \\
\hline $0 \pm 2$ day & $4(2.73-5.63)$ & $4.2(2.71-4.62)$ & 0.68 \\
\hline $14 \pm 2$ day & $4.1(2.81-7.29)$ & $4.5(3 . .67-13.45)$ & 0.15 \\
\hline $28 \pm 2$ day & $3.7(1.97-4.44)$ & $3.6(3.08-4.32)$ & 0.39 \\
\hline$p^{\mathrm{b}}$ & 0.066 & 0.013 & \\
\hline \multicolumn{4}{|c|}{ Interleukin -10 (pg/ml), median $(25-75 \mathrm{p})$} \\
\hline $0 \pm 2$ day & $11.9(5.83-37.69)$ & $10.6(7.43-27.09)$ & 0.97 \\
\hline $14 \pm 2$ day & $11.8(8.08-31.56)$ & $16.3(9.31-27.56)$ & 0.64 \\
\hline $28 \pm 2$ day & $9(6.31-14.02)$ & $12.4(6.72-17.18)$ & 0.35 \\
\hline$p^{\mathrm{b}}$ & 0.011 & 0.17 & \\
\hline \multicolumn{4}{|c|}{ Interleukin -17A (pg/ml), median (25-75 p) } \\
\hline $0 \pm 2$ day & $1.7(1.42-1.99)$ & $1.7(1.44-1.98)$ & 0.91 \\
\hline $14 \pm 2$ day & $1.7(1.42-1.97)$ & $1.6(1.43-2.02)$ & 0.86 \\
\hline $28 \pm 2$ day & $1.8(1.38-1.89)$ & $1.7(1.35-1.97)$ & 0.91 \\
\hline$p^{\mathrm{b}}$ & 0.88 & 0.96 & \\
\hline \multicolumn{4}{|c|}{ Interferon- $\gamma(\mathrm{pg} / \mathrm{ml})$, median $(25-75 \mathrm{p})$} \\
\hline $0 \pm 2$ day & $6.4(5.58-10.12)$ & $6.6(5.53-8.41)$ & 0.90 \\
\hline $14 \pm 2$ day & $6.4(6.81-11.49)$ & $7.8(7-9.53)$ & 0.42 \\
\hline $28 \pm 2$ day & $8.7(7.02-11.95)$ & $7.2(6.16-8.33)$ & 0.020 \\
\hline$p^{\mathrm{b}}$ & 0.10 & 0.33 & \\
\hline
\end{tabular}

aMann-Whitney U test; $p$ value denoting the difference between the study and the control groups.

bFriedman test; $p$ value stands for the difference among three measurements of the same cytokine in each group.

FIGURE 2. Course of the serum levels of the cytokines between groups
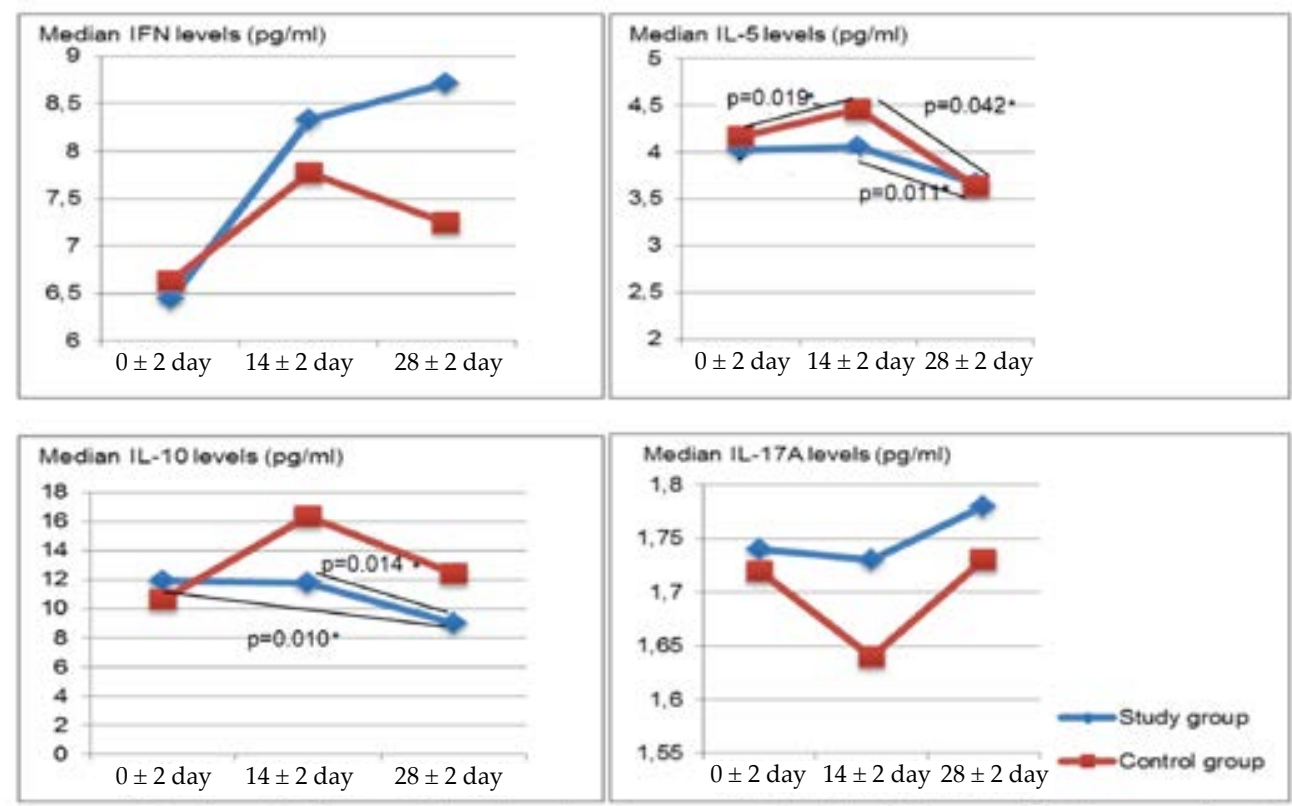

Footnote: $P$ values (Wilcoxon signed rank test) representing the differences in the serum levels of the cytokines for the study and the control group between day $0 \pm 2$ and day $14 \pm 2$ for IFN- $\gamma, 0.24$ vs. 0.15 ; IL 5, 0.53 vs. 0.019; IL-10, 0.48 vs. 0.67; IL-17-A, 0.66 vs. 0.98 ; between day $14 \pm 2$ and $28 \pm 2$ for IFN- $\gamma, 0.69$ vs. 0.36 ; IL-5, 0.042 vs. 0.011 ; IL-10, 0.014 vs. 0.053; IL-17A, 0.66-0.98; between day $0 \pm 2$ and $28 \pm 2$ for IFN- $\gamma, 0.25$ vs. 0.88 ; IL-5, 0.10 vs. 0.55 ; IL-10, 0.010 vs. 0.26 ; IL-17A, 0.94 vs. 0.88 , respectively. $\mathrm{P}^{*} ; \mathrm{P} \leq 0.05$. 
Probiotics may regulate this IL-10 signaling in the immature gut. ${ }^{21} \mathrm{IL}-10$ exhibits a strain-specific modulation together with IFN- $\gamma$, TNF- $\alpha$, and IL-12. ${ }^{12}$ L. rhamnosus GG was reported to be an anti-inflammatory probiotic because of its role in inducing IL-10 in human subjects. ${ }^{26} \mathrm{~L}$. reuteri and L. casei also promote the development of Treg cells. ${ }^{20,27}$ B. longum SP07/3 and B. bifidum MF20/5 are better inducers of IL-10 than Lactobacillus strains. ${ }^{12}$ Besides IL-10 production, all strains induced proinflammatory cytokines (IL-1b, IL-6, and TNF- $\alpha$ ) in Dong et al.'s study, which compared the immunomodulatory properties of various Lactobacillus and Bifidobacterium strains. ${ }^{12}$ Probiotic strains that induce high levels of antiinflammatory cytokines and low levels of proinflammatory cytokines have been reported to prevent colitis. ${ }^{28}$ Parallel to our results, Braat et al. reported a decreased production of IL10 in patients with Crohn disease and in healthy subjects after probiotic therapy. ${ }^{29}$ Therefore, it can be speculated that some probiotic combinations, such as the product used in this study, may increase NEC incidence or other morbidities of prematurity that develop secondary to inflammation. However, contradictory to this hypothesis, three excluded patients who developed NEC were all in the control group in our study. Nevertheless, our sample size was not sufficient to evaluate these morbidities. A recently published RCT reported an increased incidence of NEC associated with the administration of L. acidophilus and B. longum subsp. infantis in extremely preterm neonates..$^{30}$ Moreover, an increased incidence of NEC after probiotic administration in preterm pigs was reported. ${ }^{31}$

None of the probiotic strains influenced the IL-5 levels in Dong et al.'s study. ${ }^{12}$ The IL-5 levels increased significantly within the first 14 days in the control group but decreased significantly thereafter in both groups in our study. The increase in IL-5 levels in the control group during the first two weeks of life could be secondary to the higher incidence of preeclamptic mothers in this group. The study that evaluated the cytokine levels during the first week of life showed higher cytokines of the Th1 pathway in infants whose mothers had preeclampsia than the control group. ${ }^{32}$ The prevalence of CD $4+\mathrm{T}$ cells, and $\mathrm{CD} 4 / \mathrm{CD} 8$ ratio was lower in the neonates of preeclamptic mothers. ${ }^{32} \mathrm{CD} 8+\mathrm{HLA}-\mathrm{DR}+\mathrm{T}$ cells also had a significantly lower prevalence in preeeclampcia on days 0,3 , and $7 .{ }^{32}$ In another study, the Th2 and Treg levels were significantly lower in the cord blood samples of preeclamptic women than in those of healthy women, whereas, Th1 (IFN- $\gamma$ ) and Th17 (IL-17) levels were not different. ${ }^{33}$ As a result, the effect of preeclampsia on the immunophenotype of the neonates is not clear, but its potential influence on the cytokine levels of our cohort should be considered while interpreting our results.

Lactoferrin has potent immunomodulatory and broad-spectrum antimicrobial activities besides its prebiotic function. ${ }^{5}$ It decreases IL-10 levels, and severe NEC in preterm infants. ${ }^{5,34}$ As lactoferrin is a multifunctional agent, the beneficial effects on the NEC incidence may be secondary to the different mechanisms rather than the cytokine trend. The optimal dosage of lactoferrin in the management of NEC was not clear. ${ }^{5}$ Owing to the very low dose of lactoferrin $(2 \mathrm{mg})$ in our product; we can conclude that lactoferrin may only have a minor effect, if any.

IL-17A is known as a proinflammatory cytokine involved in the process of intestinal inflammation. ${ }^{21}$ It has been implicated in the pathogenesis of inflammatory bowel disease and is suppressed by Th1-derived IFN- $\gamma$ and Th2-derived IL-4. ${ }^{21}$ However, recently, the role of IL-17A has been reported to maintain the barrier function by regulating the tight junction proteins. ${ }^{21,35}$ Some probiotic strains inhibit the Th17 and IL17 activities by inducing Treg and Th1 subsets and IL-27 production. ${ }^{36}$ However, the product used in this study did not influence the IL-17 levels.

IFN- $\gamma$ is another cytokine that exhibits strainspecific modulation, and L. rhamnosus $G G$ was the only one that did not induce IFN- $\gamma$ in Dong et al.'s study. ${ }^{12}$ Formula supplemented with Saccharomyces boulardii and prebiotics was shown to downregulate IFN- $\gamma \cdot{ }^{37}$ However, we did not observe a change in the levels of IFN- $\gamma$, although the levels were higher in the study group on the $28^{\text {th }}$ day of life than in the control group. $S$. boulardii is a yeast, whereas bacteria were used in the current study. Differences can be found in the cell wall composition between bacteria and yeast, and the cell wall is responsible for the modulation of the mucosal immune response by probiotics, which can explain the different responses obtained in these studies. ${ }^{2}$

Our results are different from those of Dong et al. ${ }^{12}$ This difference may be due to the use of a preparation that contained a mixture of probiotics, prebiotics, and lactoferrin. Each component may be responsible for the changes 
observed in the cytokine levels, but interpreting the specific effect of each element is difficult, as each one has a different immunomodulatory mechanism, which is the main limitation of our study. Another limitation is that our study was performed at a single center. Most of the in vitro studies focused on cytokine production and used peripheral blood mononuclear cells. ${ }^{12}$ This cell model cannot exactly reflect the in vivo situation in which intestinal bacteria interact with Peyer's patches, M cells, etc. Comparing the results of the trials was also difficult because of the wide variations in the endpoints and the probiotics used and their doses.

There are a few reports about sepsis due to Lactobacilli strains. ${ }^{38}$ However, we did not observe sepsis. All NEC (stage-1 $[n=3]$ ) cases was in control group).

In conclusion, the combination of Lactobacillus and Bifidobacterium strains together with oligosaccharides and lactoferrin decreases the IL-5 levels after the postnatal $14^{\text {th }}$ day, and that the IL-10 levels throughout the study period, whereas, they have no effect on IFN- $\gamma$ and IL-17A. The changes in IL-10 levels may be instrumental in the development of NEC. Future studies should be focused on the biological importance of the interaction of probiotics within themselves and with other antimicrobial substances.

\section{REFERENCES}

1. Walker A. Intestinal colonization and programming of the intestinal immune response. J Clin Gastroenterol. 2014; 48(Suppl 1):S8-11.

2. SerceO, Benzer D, Gursoy T, Karatekin G, Ovali F. Efficacy of Saccharomyces boulardii on necrotizing enterocolitis or sepsis in very low birth weight infants: a randomised controlled trial. Early Hum Dev. 2013; 89(12):1033-6.

3. Johnson-Henry KC, Abrahamsson TR, Wu RY, Sherman PM. Probiotics, Prebiotics, and Symbiotics for the Prevention of Necrotizing Enterocolitis. Adv Nutr. 2016; 7(5):928-37.

4. PanigrahiP.Probiotics and prebioticsinneonatalnecrotizing enterocolitis: New opportunities for translational research. Pathophysiology. 2014; 21(1):35-46.

5. Pammi M, Suresh G. Enteral lactoferrin supplementation for prevention of sepsis and necrotizing enterocolitis in preterm infants. Cochrane Database Syst Rev. 2017; 6:CD007137.

6. Srinivasjois R, Rao S, Patole S. Prebiotic supplementation in preterm neonates: updated systematic review and metaanalysis of randomised controlled trials. Clin Nutr. 2013; 32(6):958-65.

7. Dilli D, Aydin B, Fettah ND, Ozyazici E, et al. The PropreSave study: effects of probiotics and prebiotics alone or combined on necrotizing enterocolitis in very low birth weight infants. J Pediatr. 2015; 166(3):545-51. e1.

8. Armanian AM, Sadeghnia A, Hoseinzadeh M, Mirlohi M, et al. The effect of neutral oligosaccharides on reducing the incidence of necrotizing enterocolitis in preterm infants: a randomized clinical trial. Int J Prev Med. 2014; 5(11):1387-95.

9. AlFaleh K, Anabrees J. Probiotics for prevention of necrotizing enterocolitis in preterm infants. Cochrane Database Syst Rev. 2014; (4):CD005496.

10. Sreenivasa B, Sunil Kumar P, Suresh Babu MT, Ragavendra $\mathrm{K}$. Role of symbiotics in the prevention of necrotizing enterocolitis in preterm neonates: a randomized controlled trial. Int J Contemp Pediatr. 2015; 2(2):127-30.

11. Nandhini LP, Biswal N, Adhisivam B, Mandal J, et al. Symbiotics for decreasing incidence of necrotizing enterocolitis among preterm neonates - a randomized controlled trial.JMatern Fetal Neonatal Med.2016;29(5):821-5.

12. Dong H, Rowland I, Yaqoob P. Comparative effects of six probiotic strains on immune function in vitro. Br J Nutr. 2012; 108(3):459-70.

13. Rocha-RamírezLM, Pérez-Solano RA, Castañón-AlonsoSL, Moreno Guerrero SS, et al. Probiotic Lactobacillus strains stimulate the inflammatory response and activate human macrophages. J Immunol Res. 2017; 2017:4607491.

14. Li Y, Zhou Y. Interleukin-17: the role for pathological angiogenesis in ocular neovascular diseases. Tohoku J Exp Med. 2019; 247(2):87-98.

15. Huusko JM, Karjalainen MK, Mahlman M, Haataja R, et al. A study of genes encoding cytokines (IL6, IL10, TNF), cytokine receptors (IL6R, IL6ST), and glucocorticoid receptor(NR3C1) and susceptibility to bronchopulmonary dysplasia. BMC Med Genet. 2014; 15:120.

16. Deshpande GC, Rao SC, Keil AD, Patole SK. Evidencebased guidelines for use of probiotics in preterm neonates. BMC Med. 2011; 9:92.

17. Ovali F. Intrauterine growth curves for Turkish infants born between 25 and 42 weeks of gestation. J Trop Pediatr. 2002; 49(6):381-3.

18. Walsh MC, Kliegman RM, Fanaroff AA. Necrotizing enterocolitis: a practitioner's perpective. Pediatr Rev. 1988; 9(7):219-26.

19. Papile LA, Burstein J, Burstein R, Koffler H. Incidence and evolution of subependymal and intraventricular hemorrhage: A study of infants with birth weight less than 1,500 gm. J Pediatr. 1978; 92(4):529-34.

20. Jobe AH, Bancalari E. Bronchopulmonary dysplasia. Am J Respir Crit Care Med. 2001; 163(7):1723-9.

21. Denning TL, Bhatia AM, Kane AF, Patel RM, Denning PW. Pathogenesis of NEC: Role of the innate and adaptive immune response. Semin Perinatol. 2017; 41(1):15-28.

22. Chheda S, Palkowetz KH, Garofalo R, Rassin DK, et al. Decreased interleukin-10 production by neonatal monocytes and T cells: relationship to decreased production and expression of tumor necrosis factor-alpha and its receptors. Pediatr Res. 1996; 40(3):475-83.

23. Emami CN, Chokshi N, Wang J, Hunter C, et al. Role of interleukin-10 in the pathogenesis of necrotizing enterocolitis. Am J Surg. 2012; 203(4):428-35.

24. GlockerEO, KotlarzD, Boztug K, GertzM, etal.Inflammatory bowel disease and mutations affecting the interleukin-10 receptor. N Engl J Med. 2009; 361(21):2033-45.

25. Fituch CC, Palkowetz KH, Goldman AS, Schanler RJ. Concentrations of IL-10 in preterm human milk and in milk from mothers of infants with necrotizing enterocolitis. Acta Paediatr. 2004; 93(11):1496-500.

26. Pessi T, Sütas $Y$, Hurme H, Isolauri E. Interleukin-10 generation in atopic children following oral Lactobacillus rhamnosus GG. Clin Exp Allergy. 2000; 30(12):1804-8.

27. Smits HH, Engering A, van der Kleij D, de Jong EC, et al. Selective probiotic bacteria induce IL-10-producing regulatory $\mathrm{T}$ cells in vitro by modulating dendritic cell function through dendritic cell-specific intercellular adhesion molecule 3-grabbing nonintegrin. J Allergy Clin Immunol. 2005; 115(6):1260-7.

28. Foligne B, Nutten S, Grangette C, Dennin V, et al. Correlation 
between in vitro and in vivo immunomodulatory properties of lactic acid bacteria. World J Gastroenterol. 2007; 13(2):236-43.

29. Braat $\mathrm{H}$, van den Brande $\mathrm{J}$, van Tol E, Hommes D, et al. Lactobacillus rhamnosus induces peripheral hyporesponsiveness in stimulated $\mathrm{CD} 4+\mathrm{T}$ cells via modulation of dendritic cell function. Am J Clin Nutr. 2004; 80(6):1618-25.

30. EscribanoE,Zozaya C, Madero R, Sánchez L, etal.Increased incidence of necrotizing enterocolitis associated with routine administration of Infloran ${ }^{\mathrm{TM}}$ in extremely preterm infants. Benef Microbes. 2018; 9(5):683-90.

31. Cilieborg MS, Thymann T, Siggers R, Boye M, et al. The incidence of necrotizing enterocolitis is increased following probiotic administration to preterm pigs. J Nutr. 2011; 141(2):223-30.

32. Sava F, Toldi G, Treszl A, Hajdú J, et al. Immune cell subsets, cytokine and cortisol levels during the first week of life in neonates born to pre-eclamptic mothers. Am J Reprod Immunol. 2017; 77(6):e12659.

33. Vargas-Rojas MI, Solleiro-Villavicencio H, Soto-Vega E.
Th1, Th2, Th17 and Treg levels in umbilical cord blood in preeclampsia. J Matern Fetal Neonatal Med. 2016; 29(10):1642-5.

34. Hwang SA, Kruzel ML, Actor JK. Immunomodulatory effects of recombinant lactoferrin during MRSA infection. Int Immunopharmacol. 2014; 20(1):157-63.

35. LeeJS, Tato CM, Joyce-Shaikh B, Gulen MF, et al. Interleukin23-1ndependent IL-17 production regulates intestinal epithelial permeability. Immunity. 2015; 43(4):727-38.

36. Frei R, Akdis M, O'Mahony L. Prebiotics, probiotics, synbiotics, and the immune system: experimental data and clinical evidence. Curr Opin Gastroenterol. 2015;31(2):153-8.

37. D'Souza A, Cai CL, Kumar D, Cai F, et al. Cytokines and Toll-like receptor signaling pathways in the terminal ileum of hypoxic/hyperoxic neonatal rats: benefits of probiotics supplementation. Am J Transl Res. 2012; 4(2):187-97.

38. Whelan K, Myers CE. Safety of probiotics in patients receiving nutritional support: a systematic review of case reports, randomized controlled trials, and nonrandomized trials. Am J Clin Nutr. 2010; 91(3):687-703. 